\title{
Strong Convergence Theorems for Quasi-Bregman Nonexpansive Mappings in Reflexive Banach Spaces
}

\author{
Mohammed Ali Alghamdi, ${ }^{1}$ Naseer Shahzad, ${ }^{1}$ and Habtu Zegeye ${ }^{2}$ \\ ${ }^{1}$ Department of Mathematics, King Abdulaziz University, P.O. Box 80203, Jeddah 21589, Saudi Arabia \\ ${ }^{2}$ Department of Mathematics, University of Botswana, Private Bag 00704, Gaborone, Botswana
}

Correspondence should be addressed to Naseer Shahzad; nshahzad@kau.edu.sa

Received 9 May 2014; Accepted 24 June 2014; Published 21 July 2014

Academic Editor: Giuseppe Marino

Copyright (c) 2014 Mohammed Ali Alghamdi et al. This is an open access article distributed under the Creative Commons Attribution License, which permits unrestricted use, distribution, and reproduction in any medium, provided the original work is properly cited.

\begin{abstract}
We study a strong convergence for a common fixed point of a finite family of quasi-Bregman nonexpansive mappings in the framework of real reflexive Banach spaces. As a consequence, convergence for a common fixed point of a finite family of Bergman relatively nonexpansive mappings is discussed. Furthermore, we apply our method to prove strong convergence theorems of iterative algorithms for finding a common solution of a finite family equilibrium problem and a common zero of a finite family of maximal monotone mappings. Our theorems improve and unify most of the results that have been proved for this important class of nonlinear mappings.
\end{abstract}

\section{Introduction}

Throughout this paper, $E$ is a real reflexive Banach space with the dual space $E^{*}$. The norm and the dual pair between $E^{*}$ and $E$ are denoted by $\|\cdot\|$ and $\langle\cdot, \cdot\rangle$, respectively. We also assume that $f: E \rightarrow(-\infty,+\infty]$ is a proper, lower semicontinuous, and convex function. Denote the domain of $f$ by $\operatorname{dom} f$; that is, $\operatorname{dom} f=\{x \in E: f(x)<\infty\}$. Let $x \in \operatorname{int}(\operatorname{dom} f)$. The subdifferential of $f$ at $x \in E$ is the convex set defined by

$$
\partial f(x)=\left\{x^{*} \in E^{*}: f(x)+\left\langle x^{*}, y-x\right\rangle \leq f(y), \forall y \in E\right\} .
$$

The Fenchel conjugate of $f$ is the function $f^{*}: E^{*} \rightarrow$ $(-\infty,+\infty]$ defined by $f^{*}(y)=\sup \{\langle y, x\rangle-f(x): x \in E\}$.

Let $x \in \operatorname{Dom}(f)$ and $y \in E$. The right-hand derivative of $f$ at $x$ in the direction of $y$ is defined by $f^{\circ}(x, z)=$ $\lim _{t \rightarrow 0^{+}}(f(x+t y)-f(x)) / t$. The function $f$ is called Gâteaux differentiable at $x$ if $\lim _{t \rightarrow 0^{+}}(f(x+t y)-f(x)) / t$ exists for any $y$ and hence $f^{\circ}(x, y)$ coincides with $\nabla f(x)$, the value of the gradient $\nabla f$ of $f$ at $x$. The function $f$ is said to be Gâteaux differentiable if it is Gâteaux differentiable for any $x \in$ int $\operatorname{dom} f$. Furthermore, $f$ is said to be Fréchet differentiable at $x$ if this limit is attained uniformly in $\|y\|=1$ and it is called uniformly Fréchet differentiable on a subset $C$ of $E$ if the limit is attained uniformly for $x \in C$ and $\|y\|=1$.

Let $f: E \rightarrow(-\infty,+\infty]$ be a Gâteaux differentiable function. The function $D_{f}: \operatorname{dom} f \times \operatorname{int}(\operatorname{dom} f) \rightarrow[0,+\infty)$ defined by

$$
D_{f}(x, y):=f(x)-f(y)-\langle\nabla f(y), x-y\rangle
$$

is called the Bregman distance with respect to $f$ [1].

When $E$ is a smooth Banach space, setting $f(x)=\|x\|^{2}$ for all $x \in E$, we have $\nabla f(x)=2 J x$, for all $x \in E$, where $J$ is the normalized duality mapping from $E$ into $2^{E *}$, and hence $D_{f}(x, y)$ reduces to $D_{f}(x, y)=\|x\|^{2}-2\langle x, J y\rangle+\|y\|^{2}$, for all $x, y \in E$, which is the Lyapunov function introduced by Alber [2]. If $E=H$, a Hilbert space, $J$ is identity mapping and hence $D_{f}(x, y)$ becomes $D_{f}(x, y)=\|x-y\|^{2}$, for all $x, y \in H$.

Let $C$ be a nonempty and convex subset of int $(\operatorname{dom} f)$ and let $T: C \rightarrow \operatorname{int}(\operatorname{dom} f)$ be a mapping. $T$ is said to be nonexpansive if $\|T x-T y\| \leq\|x-y\|$ for all $x, y \in C$, and $T$ is said to be quasinonexpansive if $F(T) \neq \emptyset$ and $\|T x-p\| \leq$ $\|x-p\|$, for all $x \in K$ and $p \in F(T)$, where $F(T)$ stands for the fixed point set of $T$; that is, $F(T)=\{x \in C: T x=x\}$. A point $p \in C$ is said to be an asymptotic fixed point of $T$ (see [3]) if $C$ contains a sequence $\left\{x_{n}\right\}$ which converges weakly to 
$p$ such that $\lim _{n \rightarrow \infty}\left\|x_{n}-T x_{n}\right\|=0$. The set of asymptotic fixed points of $T$ is denoted by $\widehat{F}(T)$.

A mapping $T: C \rightarrow \operatorname{int}(\operatorname{dom} f)$ with $F(T) \neq \emptyset$ is called

(i) quasi-Bregman nonexpansive [4] if

$$
D_{f}(p, T x) \leq D_{f}(p, x), \quad \forall x \in C, p \in F(T) ;
$$

(ii) Bregman relatively nonexpansive [4] if

$$
\begin{gathered}
D_{f}(p, T x) \leq D_{f}(p, x), \quad \forall x \in C, p \in F(T), \\
\widehat{F}(T)=F(T) ;
\end{gathered}
$$

(iii) Bregman firmly nonexpansive [5] if, for all $x, y \in C$,

$$
\begin{aligned}
& \langle\nabla f(T x)-\nabla f(T y), T x-T y\rangle \\
& \quad \leq\langle\nabla f(x)-\nabla f(y), T x-T y\rangle
\end{aligned}
$$

or, equivalently,

$$
\begin{aligned}
& D_{f}(T x, T y)+D_{f}(T y, T x)+D_{f}(T x, x)+D_{f}(T y, y) \\
& \leq D_{f}(T x, y)+D_{f}(T y, x) .
\end{aligned}
$$

Iterative methods for approximating fixed points of nonexpansive, quasinonexpansive mappings and their generalizations have been studied by various authors (see, e.g., [6-16] and the references therein) in Hilbert spaces. But extending this theory to Banach spaces encountered some difficulties because the useful examples of nonexpansive operators in Hilbert spaces are no longer nonexpansive in Banach spaces (e.g., the resolvent $R_{A}=(I+r A)^{-1}$, for $r>0$, of a monotone mapping $A: C \rightarrow 2^{H}$ and the metric projection $P_{C}$ onto a nonempty, closed, and convex subset $C$ of $H$ ). To overcome these difficulties, Bregman [1] discovered techniques with the use of Bregman distance function $D_{f}(\cdot, \cdot)$ instead of norm in the process of designing and analyzing feasibility and optimization problems. This opened a growing area of research for solving variational inequalities and approximating solutions or fixed points of nonlinear mappings (see, e.g., $[1,17-21]$ and the references therein).

The existence and approximation of fixed points of Bregman firmly nonexpansive mappings were studied in [5]. It is also known that if $T$ is Bregman firmly nonexpansive and $f$ is Legendre function which is bounded, uniformly Frêchet differentiable, and totally convex on bounded subsets of $E$, then $F(T)=\widehat{F}(T)$ and $F(T)$ is closed and convex (see [5]). It also follows that every Bregman firmly nonexpansive mapping is Bregman relatively nonexpansive and hence quasi-Bregman nonexpansive mapping.

A Bregman projection [1] of $x \in \operatorname{int}(\operatorname{dom} f)$ onto the nonempty closed and convex set $C \subset \operatorname{dom} f$ is the unique vector $P_{C}^{f}(x) \in C$ satisfying

$$
D_{f}\left(P_{C}^{f}(x), x\right)=\inf \left\{D_{f}(y, x): y \in C\right\} .
$$

Remark 1. If $E$ is a smooth Banach space and $f(x)=\|x\|^{2}$ for all $x \in E$, then the Bregman projection $P_{C}^{f}(x)$ reduces to the generalized projection $\Pi_{C}(x)$ (see, e.g., [2]) which is defined by

$$
\phi\left(\Pi_{C}(x), x\right)=\min _{y \in C} \phi(y, x),
$$

where $\phi(y, x)=\|y\|^{2}-2\langle y, J x\rangle+\|x\|^{2}$.

Very recently, by using Bregman projection, Reich and Sabach [4] introduced an algorithm for finding a common zero of many finitely maximal monotone mappings $A_{i}: E \rightarrow$ $E(i=1,2, \ldots, N)$ satisfying $\mathscr{F}:=\bigcap_{i=1}^{N} A_{i}^{-1}(0) \neq \emptyset$ in a reflexive Banach space $E$ as follows:

$$
\begin{aligned}
x_{0} & \in E, \quad \text { chosen arbitrarily, } \\
y_{n}^{i} & =\operatorname{Res}_{\lambda_{n}^{i} A_{i}}^{f}\left(x_{n}+e_{n}^{i}\right), \\
C_{n}^{i} & =\left\{z \in E: D_{f}\left(z, y_{n}^{i}\right) \leq D_{f}\left(z, x_{n}+e_{n}^{i}\right)\right\}, \\
C_{n} & :=\bigcap_{i=1}^{N} C_{n}^{i}, \\
Q_{n} & =\left\{z \in E:\left\langle\nabla f\left(x_{0}\right)-\nabla f\left(x_{n}\right), z-x_{n}\right\rangle \leq 0\right\}, \\
x_{n+1} & =P_{C_{n} \cap Q_{n}}^{f}\left(x_{0}\right), \quad \forall n \geq 0,
\end{aligned}
$$

where $\operatorname{Res}_{r A}^{f}:=(\nabla f+r A)^{-1}(\nabla f)$. Under suitable conditions, they proved that if, for each $i=1,2, \ldots, N$, we have that $\liminf _{n \rightarrow \infty} \lambda_{n}^{i}>0$ and the sequences of errors $\left\{e_{n}^{i}\right\} \subset E$ satisfy $\liminf _{n \rightarrow \infty} e_{n}^{i}=0$, then the sequence $\left\{x_{n}\right\}$ converges strongly to $P_{\mathscr{F}}^{f}\left(x_{0}\right)$.

In [22], Reich and Sabach proposed an algorithm for finding a common fixed point of many finitely Bregman firmly nonexpansive mappings $T_{i}: C \rightarrow C(i=1,2, \ldots, N)$ satisfying $\bigcap_{i=1}^{N} F\left(T_{i}\right) \neq \emptyset$ in a reflexive Banach space $E$ as follows:

$$
\begin{gathered}
x_{0} \in E, \quad \text { chosen arbitrarily, } \\
Q_{0}^{i}=E, \\
y_{n}^{i}=T_{i}\left(x_{n}+e_{n}^{i}\right), \\
Q_{n+1}^{i}=\left\{z \in Q_{n}^{i}:\left\langle\nabla f\left(x_{n}+e_{n}^{i}\right)-\nabla f\left(y_{n}^{i}\right), z-y_{n}^{i}\right\rangle \leq 0\right\}, \\
Q_{n}=\bigcap_{i=1}^{N} Q_{n}^{i}, \\
x_{n+1}=P_{Q_{n+1}^{f}}^{f}\left(x_{0}\right), \quad \forall n \geq 0 .
\end{gathered}
$$

They proved that, under suitable conditions, the sequence $\left\{x_{n}\right\}$ generated by (10), converges strongly to $\bigcap_{i=1}^{N} F\left(T_{i}\right)$ and applied it to the solution of convex feasibility and equilibrium problems. 
Remark 2. But it is worth mentioning that the iteration processes (9) and (10) seem difficult in the sense that, at each stage of iteration, the set(s) $C_{n}$ and/or $Q_{n}$ are/is computed and the next iterate is taken as the Bregman projection of $x_{0}$ onto the intersection of $C_{n}$ and/or $Q_{n}$. This seems difficult to do in applications.

In this paper, we investigate an iterative scheme for finding a common fixed point of a finite family of quasiBregman nonexpansive mappings in reflexive Banach spaces. We prove strong convergence theorems for the sequences produced by the method. Furthermore, we apply our method to prove strong convergence theorems for finding a solution of a finite family of equilibrium problems and for finding a common zero of a finite family of maximal monotone mappings. Our results improve and generalize many known results in the current literature (see, e.g., $[4,23]$ )

\section{Preliminaries}

Let $f: E \rightarrow(-\infty,+\infty]$ be a Gâteaux differentiable function. The function $f$ is said to be essentially smooth if $\partial f$ is both locally bounded and single-valued on its domain. It is called essentially strictly convex, if $(\partial f)^{-1}$ is locally bounded on its domain and is strictly convex on every convex subset of $\operatorname{dom} \partial f$. $f$ is said to be a Legendre, if it is both essentially smooth and essentially strictly convex. When the subdifferential of $f$ is single-valued, it coincides with the gradient $\partial f=\nabla f$ (see [24]).

We note that if $E$ is a reflexive Banach space, then we have the following.

(i) $f$ is essentially smooth if and only if $f^{*}$ is essentially strictly convex (see [25, Theorem 5.4]).

(ii) $(\partial f)^{-1}=\partial f^{*}$ (see [26]).

(iii) $f$ is Legendre if and only if $f^{*}$ is Legendre (see [25, Corollary 5.5]).

(iv) If $f$ is Legendre, then $\nabla f$ is a bijection satisfying $\nabla f=\left(\nabla f^{*}\right)^{-1}, \operatorname{ran} \nabla f=\operatorname{dom} \nabla f^{*}=\operatorname{int} \operatorname{dom} f^{*}$, and $\operatorname{ran} \nabla f^{*}=\operatorname{dom} \nabla f=\operatorname{int} \operatorname{dom} f$ (see [25, Theorem 5.10]).

When $E$ is a smooth and strictly convex Banach space, one important and interesting example of Legendre function is $f(x):=(1 / p)\|x\|^{p}(1<p<\infty)$. In this case the gradient $\nabla f$ of $f$ coincides with the generalized duality mapping of $E$; that is, $\nabla f=J_{p}(1<p<\infty)$. In particular, $\nabla f=I$, the identity mapping in Hilbert spaces.

Let $E$ be a Banach space and let $B_{r}:=\{z \in E:\|z\| \leq r\}$, for all $r>0$ and $S_{E}=\{x \in E:\|x\|=1\}$. Then a function $f: E \rightarrow \mathbb{R}$ is said to be uniformly convex on bounded subsets of $E$ [27, page 203] if $\rho_{r}(t)>0$, for all $r, t>0$, where $\rho_{r}$ : $[0, \infty) \rightarrow[0, \infty]$ is defined by

$$
\begin{aligned}
\rho_{r}(t):=\inf _{x, y \in B_{r},\|x-y\|=t, \alpha \in(0,1)}( & \alpha f(x)+(1-\alpha) f(y) \\
& -f(\alpha x+(1-\alpha) y)) \\
\times & (\alpha(1-\alpha))^{-1},
\end{aligned}
$$

for all $t \geq 0$. The function $\rho_{r}$ is called the gauge of uniform convexity of $f$. The function $f$ is also said to be uniformly smooth on bounded subsets of $E$ [27, page 207] if $\lim _{t \rightarrow 0^{+}}\left(\sigma_{r}(t) / t\right)=0$, for all $r>0$, where $\sigma_{r}:[0, \infty) \rightarrow$ $[0, \infty]$ is defined by

$$
\begin{aligned}
\sigma_{r}(t):=\sup _{x \in B_{r}, y \in S_{E}, \alpha \in(0,1)}( & \alpha f(x+(1-\alpha) t y) \\
& +(1-\alpha) f(x-\alpha t y)-f(x)) \\
& \times(\alpha(1-\alpha))^{-1},
\end{aligned}
$$

for all $t \geq 0$.

In the sequel, we will need the following lemmas.

Lemma 3 (see [28]). Let $E$ be a Banach space, let $r>0$ be a constant, and let $f: E \rightarrow \mathbb{R}$ be a uniformly convex on bounded subsets of $E$. Then

$$
f\left(\sum_{k=0}^{n} \alpha_{k} x_{k}\right) \leq \sum_{k=0}^{n} \alpha_{k} f\left(x_{k}\right)-\alpha_{i} \alpha_{j} \rho_{r}\left(\left\|x_{i}-y_{j}\right\|\right),
$$

for all $i, j \in\{0,1,2, \ldots, n\}, x_{k} \in B r, \alpha_{k} \in(0,1)$, and $k=$ $0,1,2, \ldots, n$ with $\sum_{k=0}^{n} \alpha_{k}=1$, where $\rho_{r}$ is the gauge of uniform convexity of $f$.

Lemma 4 (see [24]). Let $f: E \rightarrow(-\infty,+\infty]$ be a proper, lower semicontinuous, and convex function; then $f^{*}$ : $E^{*} \rightarrow(-\infty,+\infty]$ is a proper, weak ${ }^{*}$ lower semicontinuous, and convex function. Thus, for all $z \in E$, we have

$$
D_{f}\left(z, \nabla f^{*}\left(\sum_{i=1}^{N} t_{i} \nabla f\left(x_{i}\right)\right)\right) \leq \sum_{i=1}^{N} t_{i} D_{f}\left(z, x_{i}\right) .
$$

Lemma 5 (see [29]). Let $f: E \rightarrow \mathbb{R}$ be a Gâteaux differentiable on $\operatorname{int}(\operatorname{dom} f)$ such that $\nabla f^{*}$ is bounded on bounded subsets of $\operatorname{dom} f^{*}$. Let $x^{*} \in X$ and $\left\{x_{n}\right\} \subset$ E. If $\left\{D_{f}\left(x, x_{n}\right)\right\}$ is bounded, so is the sequence $\left\{x_{n}\right\}$.

A function $f$ on $E$ is coercive [30] if the sublevel set of $f$ is bounded; equivalently, $\lim _{\|x\| \rightarrow \infty} f(x)=\infty$. A function $f$ on $E$ is said to be strongly coercive [27] if $\lim _{\|x\| \rightarrow \infty} f(x) /\|x\|=$ $\infty$.

Lemma 6 (see [27]). Let $E$ be a reflexive Banach space and let $f: E \rightarrow \mathbb{R}$ be a continuous convex function which is strongly coercive. Then the following assertions are equivalent.

(1) $f$ is bounded on bounded subsets and uniformly smooth on bounded subsets of E;

(2) $f^{*}$ is Fréchet differentiable and $\nabla f^{*}$ is uniformly normto-norm continuous on bounded subsets of $E^{*}$;

(3) $\operatorname{dom} f=E^{*}, f^{*}$ is strongly coercive and uniformly convex on bounded subsets of $E^{*}$.

Lemma 7 (see [5]). Let $f: E \rightarrow(-\infty,+\infty]$ be a Legendre function. Let $C$ be a nonempty closed convex subset of $\operatorname{int}(\operatorname{dom} f)$ and let $T: C \rightarrow C$ be a quasi-Bregman nonexpansive mapping. Then $F(T)$ is closed and convex. 
Let $f: E \rightarrow(-\infty,+\infty]$ be a Gâteaux differentiable function. The modulus of total convexity of $f$ at $x \in \operatorname{dom}$ $f$ is the function $\nu_{f}(x, \cdot):[0,+\infty) \rightarrow[0,+\infty]$ defined by

$$
v_{f}(x, t):=\inf \left\{D_{f}(y, x): y \in \operatorname{dom} f,\|y-x\|=t\right\} .
$$

The function $f$ is called totally convex at $x$ if $v_{f}(x, t)>0$, whenever $t>0$. The function $f$ is called totally convex if it is totally convex at any point $x \in \operatorname{int}(\operatorname{dom} f)$ and is said to be totally convex on bounded sets if $v_{f}(B, t)>0$ for any nonempty bounded subset $B$ of $E$ and $t>0$, where the modulus of total convexity of the function $f$ on the set $B$ is the function $v_{f}: \operatorname{int} \operatorname{dom} f \times[0,+\infty) \rightarrow[0,+\infty]$ defined by

$$
v_{f}(B, t):=\inf \left\{v_{f}(x, t): x \in B \cap \operatorname{dom} f\right\} .
$$

We know that $f$ is totally convex on bounded sets if and only if $f$ is uniformly convex on bounded sets (see [18, Theorem 2.10]). The following lemmas will be useful in the proof of our main results.

Lemma 8 (see [31]). The function $f: E \rightarrow(-\infty,+\infty)$ is totally convex on bounded subsets of $E$ if and only if, for any two sequences $\left\{x_{n}\right\}$ and $\left\{y_{n}\right\}$ in $\operatorname{int}(\operatorname{dom} f)$ and $\operatorname{dom} f$, respectively, such that the first one is bounded,

$$
\lim _{n \rightarrow \infty} D_{f}\left(y_{n}, x_{n}\right)=0 \Longrightarrow \lim _{n \rightarrow \infty}\left\|y_{n}-x_{n}\right\|=0 \text {. }
$$

Lemma 9 (see $[27,32]$ ). Let $f: E \rightarrow \mathbb{R}$ be a strongly coercive and uniformly convex on bounded subsets of $E$; then $f^{*}$ is bounded on bounded sets and uniformly Fréchet differentiable on bounded subsets of $E^{*}$.

Lemma 10 (see [33]). Let $f: E \rightarrow(-\infty,+\infty]$ be uniformly Fréchet differentiable and bounded on bounded sets of $E$; then $\nabla f$ is uniformly continuous on bounded subsets of $E$ from the strong topology of $E$ to the strong topology of $E^{*}$.

Lemma 11 (see [18]). Let $C$ be a nonempty, closed, and convex subset of $E$. Let $f: E \rightarrow \mathbb{R}$ be a Gâteaux differentiable and totally convex function and let $x \in E$; then

(i) $z=P_{C}^{f}(x)$ if and only if $\langle\nabla f(x)-\nabla f(z), y-z\rangle \leq$ $0, \forall y \in C$.

(ii) $D_{f}\left(y, P_{C}^{f}(x)\right)+D_{f}\left(P_{C}^{f}(x), x\right) \leq D_{f}(y, x), \forall y \in C$.

Let $f: E \rightarrow \mathbb{R}$ be a Legendre and Gâteaux differentiable function. Following $[2,34]$, we make use of the function $V_{f}$ : $E \times E^{*} \rightarrow[0,+\infty)$ associated with $f$, which is defined by

$V_{f}\left(x, x^{*}\right)=f(x)-\left\langle x, x^{*}\right\rangle+f^{*}\left(x^{*}\right), \quad \forall x \in E, x^{*} \in E^{*}$.

Then $V_{f}$ is nonnegative and

$$
V_{f}\left(x, x^{*}\right)=D_{f}\left(x, \nabla f^{*}\left(x^{*}\right)\right) \quad \forall x \in E, x^{*} \in E^{*} .
$$

Moreover, by the subdifferential inequality,

$$
V_{f}\left(x, x^{*}\right)+\left\langle y^{*}, \nabla f^{*}\left(x^{*}\right)-x\right\rangle \leq V_{f}\left(x, x^{*}+y^{*}\right),
$$

where $\forall x \in E$ and $x^{*}, y^{*} \in E^{*}$ (see [35]).
Lemma 12 (see [36]). Let $\left\{a_{n}\right\}$ be a sequence of nonnegative real numbers satisfying the following relation:

$$
a_{n+1} \leq\left(1-\alpha_{n}\right) a_{n}+\alpha_{n} \delta_{n}, \quad n \geq n_{0},
$$

where $\left\{\alpha_{n}\right\} \subset(0,1)$ and $\left\{\delta_{n}\right\} \subset \mathbb{R}$ satisfying the following conditions: $\lim _{n \rightarrow \infty} \alpha_{n}=0, \quad \sum_{n=1}^{\infty} \alpha_{n}=\infty$ and $\lim \sup _{n \rightarrow \infty} \delta_{n} \leq 0$. Then, $\lim _{n \rightarrow \infty} a_{n}=0$.

Lemma 13 (see [37]). Let $\left\{a_{n}\right\}$ be sequences of real numbers such that there exists a subsequence $\left\{n_{i}\right\}$ of $\{n\}$ such that $a_{n_{i}}<$ $a_{n_{i}+1}$ for all $i \in \mathbb{N}$. Then there exists an increasing sequence $\left\{m_{k}\right\} \subset \mathbb{N}$ such that $m_{k} \rightarrow \infty$ and the following properties are satisfied by all (sufficiently large) numbers $k \in \mathbb{N}$ :

$$
a_{m_{k}} \leq a_{m_{k}+1}, \quad a_{k} \leq a_{m_{k}+1}
$$

In fact, $m_{k}$ is the largest number $n$ in the set $\{1,2, \ldots, k\}$ such that the condition $a_{n} \leq a_{n+1}$ holds.

\section{Main Results}

We now prove the following theorem.

Theorem 14. Let $f: E \rightarrow \mathbb{R}$ be a strongly coercive Legendre function which is bounded, uniformly Fréchet differentiable, and totally convex on bounded subsets of E. Let $C$ be a nonempty, closed, and convex subset of int(dom $f)$ and let $T_{i}: C \rightarrow C$, for $i=1,2, \ldots, N$, be a finite family of quasiBregman nonexpansive mappings such that $\widehat{F}\left(T_{i}\right)=F\left(T_{i}\right)$, for $i=1,2, \ldots, N$. Assume that $\mathscr{F}:=\bigcap_{i=1}^{N} F\left(T_{i}\right)$ is nonempty. For $u, x_{0} \in C$ let $\left\{x_{n}\right\}$ be a sequence generated by

$$
\begin{gathered}
y_{n}=P_{C}^{f} \nabla f^{*}\left(\alpha_{n} \nabla f(u)+\left(1-\alpha_{n}\right) \nabla f\left(x_{n}\right)\right), \\
x_{n+1}=\nabla f^{*}\left(\beta_{0} \nabla f\left(y_{n}\right)+\sum_{i=1}^{N} \beta_{i} \nabla f\left(T_{i} y_{n}\right)\right), \quad \forall n \geq 0,
\end{gathered}
$$

where $\left\{\alpha_{n}\right\} \subset(0,1)$ and $\left\{\beta_{i}\right\}_{i=0}^{N} \subset[c, d] \subset(0,1)$ satisfying $\lim _{n \rightarrow \infty} \alpha_{n}=0, \sum_{n=1}^{\infty} \alpha_{n}=\infty$, and $\sum_{i=0}^{N} \beta_{i}=1$. Then, $\left\{x_{n}\right\}$ converges strongly to $p=P_{\mathscr{F}}^{f}(u)$.

Proof. Lemma 7 ensures that each $F\left(T_{i}\right)$, for $i \in\{1,2, \ldots, N\}$, and $\mathscr{F}$ are closed and convex. Thus, $P_{\mathscr{F}}^{f}$ is well defined. Let $p=P_{\mathscr{F}}^{f}(u)$. Then, from (23), Lemmas 11 and 4 , and property of $D_{f}$ we get that

$$
\begin{aligned}
D_{f}\left(p, y_{n}\right) & =D_{f}\left(p, P_{C}^{f} \nabla f^{*}\left(\alpha_{n} \nabla f(u)+\left(1-\alpha_{n}\right) \nabla f\left(x_{n}\right)\right)\right) \\
& \leq D_{f}\left(p, \nabla f^{*}\left(\alpha_{n} \nabla f(u)+\left(1-\alpha_{n}\right) \nabla f\left(x_{n}\right)\right)\right) \\
& =\alpha_{n} D_{f}(p, u)+\left(1-\alpha_{n}\right) D_{f}\left(p, x_{n}\right) .
\end{aligned}
$$


Moreover, from (23), (18), and (19) we get that

$$
\begin{aligned}
D_{f}\left(p, x_{n+1}\right)= & D_{f}\left(p, \nabla f^{*}\left(\beta_{0} \nabla f\left(y_{n}\right)+\sum_{i=1}^{N} \beta_{i} \nabla f\left(T_{i} y_{n}\right)\right)\right) \\
= & V\left(p, \beta_{0} \nabla f\left(y_{n}\right)+\sum_{i=1}^{N} \beta_{i} \nabla f\left(T_{i} y_{n}\right)\right) \\
= & f(p)-\left\langle p, \beta_{0} \nabla f\left(y_{n}\right)+\sum_{i=1}^{N} \beta_{i} \nabla f\left(T_{i} y_{n}\right)\right\rangle \\
& +f^{*}\left(\beta_{0} \nabla f\left(y_{n}\right)+\sum_{i=1}^{N} \beta_{i} \nabla f\left(T_{i} y_{n}\right)\right) .
\end{aligned}
$$

Since $f$ is uniformly Fréchet differentiable function we have that $f$ is uniformly smooth and hence by Theorem 3.5.5 of [27] we get that $f^{*}$ is uniformly convex. This, with Lemmas 3 and (24), gives that

$$
\begin{aligned}
D_{f}\left(p, x_{n+1}\right) \leq & f(p)-\beta_{0}\left\langle p, \nabla f\left(y_{n}\right)\right\rangle \\
& -\sum_{i=1}^{N} \beta_{i}\left\langle p, \nabla f\left(T_{i} y_{n}\right)\right\rangle \\
& +\beta_{0} f^{*}\left(\nabla f\left(y_{n}\right)\right)+\sum_{i=1}^{N} \beta_{i} f^{*}\left(\nabla f\left(T_{i} y_{n}\right)\right) \\
& -\beta_{0} \beta_{i} \rho_{r}^{*}\left(\left\|\nabla f\left(y_{n}\right)-\nabla f\left(T_{i} x_{n}\right)\right\|\right) \\
= & \beta_{0} V\left(p, \nabla f\left(y_{n}\right)\right)+\sum_{i=1}^{N} \beta_{i} V\left(p, \nabla f\left(T y_{n}\right)\right) \\
& -\beta_{0} \beta_{i} \rho_{r}^{*}\left(\left\|\nabla f\left(y_{n}\right)-\nabla f\left(T_{i} x_{n}\right)\right\|\right) \\
= & \beta_{0} D_{f}\left(p, y_{n}\right)+\sum_{i=1}^{N} \beta_{i} D_{f}\left(p, T y_{n}\right) \\
& -\beta_{0} \beta_{i} \rho_{r}^{*}\left(\left\|\nabla f\left(y_{n}\right)-\nabla f\left(T_{i} x_{n}\right)\right\|\right) \\
\leq & \alpha_{n} D_{f}(p, u)+\left(1-\alpha_{n}\right) D_{f}\left(p, x_{n}\right), \\
\leq & \beta_{0} D_{f}\left(p, y_{n}\right)+\sum_{i=1}^{N} \beta_{i} D_{f}\left(p, y_{n}\right) \\
& -\beta_{0} \beta_{i} \rho_{r}^{*}\left(\left\|\nabla f\left(y_{n}\right)-\nabla f\left(T_{i} x_{n}\right)\right\|\right) \\
\leq & \left.y_{n}\right)-\beta_{0} \beta_{i} \rho_{r}^{*}\left(\left\|\nabla f\left(y_{n}\right)-\nabla f\left(T_{i} y_{n}\right)\right\|\right) \\
&
\end{aligned}
$$

for each $i \in\{1,2, \ldots, N\}$. Thus, by induction,

$$
D_{f}\left(p, x_{n+1}\right) \leq \max \left\{D_{f}(p, u), D_{f}\left(p, x_{0}\right)\right\}, \quad \forall n \geq 0,
$$

which implies that $\left\{x_{n}\right\}$ is bounded. Now, let $z_{n}=$ $\nabla f^{*}\left(\alpha_{n} \nabla f(u)+\left(1-\alpha_{n}\right) \nabla f\left(x_{n}\right)\right)$. Then we note that $y_{n}=P_{C}^{f} z_{n}$.
Since $f$ is strongly coercive, uniformly convex, uniformly Fréchet differentiable, and bounded on bounded subsets of $E$ by Lemmas 10,9 , and 6 we have that $\nabla f$ and $\nabla f^{*}$ are bounded on bounded sets and hence $\left\{z_{n}\right\}$ and $\left\{y_{n}\right\}$ are bounded. In addition, using (19), (20), and property of $D_{f}$ we obtain that

$$
\begin{aligned}
D_{f}\left(p, y_{n}\right) \leq & D_{f}\left(p, z_{n}\right)=V\left(p, \nabla f\left(z_{n}\right)\right) \\
\leq & V\left(p, \nabla f\left(z_{n}\right)-\alpha_{n}(\nabla f(u)-\nabla f(p))\right) \\
& +\alpha_{n}\left\langle\nabla f(u)-\nabla f(p), z_{n}-p\right\rangle \\
= & D_{f}\left(p, \nabla f^{*}\left(\alpha_{n} \nabla f(p)+\left(1-\alpha_{n}\right) \nabla f\left(x_{n}\right)\right)\right) \\
& +\alpha_{n}\left\langle\nabla f(u)-\nabla f(p), z_{n}-p\right\rangle \\
\leq & \alpha_{n} D_{f}(p, p)+\left(1-\alpha_{n}\right) D_{f}\left(p, x_{n}\right) \\
& +\alpha_{n}\left\langle\nabla f(u)-\nabla f(p), z_{n}-p\right\rangle \\
= & \left(1-\alpha_{n}\right) D_{f}\left(p, x_{n}\right) \\
& +\alpha_{n}\left\langle\nabla f(u)-\nabla f(p), z_{n}-p\right\rangle .
\end{aligned}
$$

Furthermore, from (26) and (29) we have that

$$
\begin{aligned}
D_{f}\left(p, x_{n+1}\right) \leq & \left(1-\alpha_{n}\right) D_{f}\left(p, x_{n}\right) \\
& +\alpha_{n}\left\langle\nabla f(u)-\nabla f(p), z_{n}-p\right\rangle \\
& -\beta_{0} \beta_{i} \rho_{r}^{*}\left(\left\|\nabla f\left(y_{n}\right)-\nabla f\left(T_{i} y_{n}\right)\right\|\right) \\
\leq & \left(1-\alpha_{n}\right) D_{f}\left(p, x_{n}\right) \\
& +\alpha_{n}\left\langle\nabla f(u)-\nabla f(p), z_{n}-p\right\rangle .
\end{aligned}
$$

Now, we consider two cases.

Case 1. Suppose that there exists $n_{0} \in \mathbb{N}$ such that $\left\{D_{f}\left(p, x_{n}\right)\right\}$ is nonincreasing for all $n \geq n_{0}$. In this situation, $\left\{D_{f}\left(p, x_{n}\right)\right\}$ is convergent. Then, from (30) we have that

$$
\beta_{0} \beta_{i} \rho_{r}^{*}\left(\left\|\nabla f\left(y_{n}\right)-\nabla f\left(T_{i} y_{n}\right)\right\|\right) \longrightarrow 0
$$

which implies, by the property of $\rho_{r}^{*}$, that

$$
\nabla f\left(y_{n}\right)-\nabla f\left(T_{i} y_{n}\right) \longrightarrow 0, \quad \text { as } n \longrightarrow \infty
$$

Now, since $f$ is a strongly coercive and uniformly convex on bounded subsets of $E, f^{*}$ is uniformly Fréchet differentiable on bounded subsets of $E^{*}$ (see [27, Proposition 3.6.2]) and $f$ is Legendre; we have by Lemma 10 that

$$
y_{n}-T_{i} y_{n} \longrightarrow 0, \quad \text { as } n \longrightarrow \infty \text {, }
$$

for each $i \in\{1,2, \ldots, N\}$. 
Furthermore, Lemma 11, property of $D_{f}$, and the fact that $\alpha_{n} \rightarrow 0$, as $n \rightarrow \infty$, imply that

$$
\begin{aligned}
D_{f}\left(x_{n}, y_{n}\right)= & D_{f}\left(x_{n}, P_{C}^{f} z_{n}\right) \leq D_{f}\left(x_{n}, z_{n}\right) \\
= & D_{f}\left(x_{n}, \nabla f^{*}\left(\alpha_{n} \nabla f(u)+\left(1-\alpha_{n}\right) \nabla f\left(x_{n}\right)\right)\right) \\
\leq & \alpha_{n} D_{f}\left(x_{n}, u\right)+\left(1-\alpha_{n}\right) D_{f}\left(x_{n}, x_{n}\right) \\
\leq & \alpha_{n} D_{f}\left(x_{n}, u\right) \\
& +\left(1-\alpha_{n}\right) D_{f}\left(x_{n}, x_{n}\right) \longrightarrow 0 \text { as } n \longrightarrow \infty
\end{aligned}
$$

and hence by Lemma 8 we get that

$$
x_{n}-y_{n} \longrightarrow 0, \quad x_{n}-z_{n} \longrightarrow 0, \quad n \longrightarrow \infty .
$$

Since $\left\{z_{n}\right\}$ is bounded and $E$ is reflexive, we choose a subsequence $\left\{z_{n_{j}}\right\}$ of $\left\{z_{n}\right\}$ such that $z_{n_{j}} \rightarrow z$ and $\limsup _{n \rightarrow \infty}\left\langle\nabla f(u)-\nabla f(p), z_{n}-p\right\rangle=\lim _{j \rightarrow \infty}\langle\nabla f(u)-$ $\left.\nabla f(p), z_{n_{j}}-p\right\rangle$. Then, from (36) we get that

$$
y_{n_{j}} \rightarrow z, \quad \text { as } j \longrightarrow \infty \text {. }
$$

Thus, from (34) and the fact that $\widehat{F}\left(T_{i}\right)=F\left(T_{i}\right)$ we obtain that $z \in F\left(T_{i}\right)$, for each $i \in\{1,2, \ldots, N\}$ and hence $z \in \bigcap_{i=1}^{N} F\left(T_{i}\right)$.

Therefore, by Lemma 11, we immediately obtain that $\limsup _{n \rightarrow \infty}\left\langle\nabla f(u)-\nabla f(p), z_{n}-p\right\rangle=\lim _{j \rightarrow \infty}\langle\nabla f(u)-$ $\left.\nabla f(p), z_{n_{j}}-p\right\rangle=\langle\nabla f(u)-\nabla f(p), z-p\rangle \leq 0$. It follows from Lemma 12 and (31) that $D_{f}\left(p, x_{n}\right) \rightarrow 0$, as $n \rightarrow \infty$. Consequently, by Lemma 8 we obtain that $x_{n} \rightarrow p$.

Case 2. Suppose that there exists a subsequence $\left\{n_{j}\right\}$ of $\{n\}$ such that

$$
D_{f}\left(p, x_{n_{j}}\right)<D_{f}\left(p, x_{n_{j}+1}\right)
$$

for all $j \in \mathbb{N}$. Then, by Lemma 13, there exists a nondecreasing sequence $\left\{m_{k}\right\} \subset \mathbb{N}$ such that $m_{k} \rightarrow \infty, D_{f}\left(p, x_{m_{k}}\right) \leq$ $D_{f}\left(p, x_{m_{k}+1}\right)$ and $D_{f}\left(p, x_{k}\right) \leq D_{f}\left(p, x_{m_{k}+1}\right)$, for all $k \in \mathbb{N}$. Then from (30) and the fact that $\alpha_{n} \rightarrow 0$ we obtain that

$$
\rho_{r}^{*}\left(\left\|\nabla f\left(y_{m_{k}}\right)-\nabla f\left(T_{i} y_{m_{k}}\right)\right\|\right) \longrightarrow 0, \quad \text { as } k \longrightarrow \infty \text {, }
$$

for each $i \in\{1,2, \ldots, N\}$. Thus, following the method of proof of Case 1, we obtain that $y_{m_{k}}-T_{i} y_{m_{k}} \rightarrow 0, x_{m_{k}}-y_{m_{k}} \rightarrow 0$, $x_{m_{k}}-z_{m_{k}} \rightarrow 0$, as $k \rightarrow \infty$, and hence we obtain that

$$
\limsup _{k \rightarrow \infty}\left\langle\nabla f(u)-\nabla f(p), z_{m_{k}}-p\right\rangle \leq 0 .
$$

Then from (31) we have that

$$
\begin{aligned}
D_{f}\left(p, x_{m_{k}+1}\right) \leq & \left(1-\alpha_{m_{k}}\right) D_{f}\left(p, x_{m_{k}}\right) \\
& +\alpha_{m_{k}}\left\langle\nabla f(u)-\nabla f(p), z_{m_{k}}-p\right\rangle .
\end{aligned}
$$

Now, since $D_{f}\left(p, x_{m_{k}}\right) \leq D_{f}\left(p, x_{m_{k}+1}\right)$, inequality (41) implies that

$$
\begin{aligned}
\alpha_{m_{k}} D_{f}\left(p, x_{m_{k}}\right) \leq & D_{f}\left(p, x_{m_{k}}\right)-D_{f}\left(p, x_{m_{k}+1}\right) \\
& +\alpha_{m_{k}}\left\langle\nabla f(u)-\nabla f(p), z_{m_{k}}-p\right\rangle \\
\leq & \alpha_{m_{k}}\left\langle\nabla f(u)-\nabla f(p), z_{m_{k}}-p\right\rangle .
\end{aligned}
$$

In particular, since $\alpha_{m_{k}}>0$, we get

$$
D_{f}\left(p, x_{m_{k}}\right) \leq\left\langle\nabla f(u)-\nabla f(p), z_{m_{k}}-p\right\rangle \text {. }
$$

Then, from (40) we obtain $D_{f}\left(p, x_{m_{k}}\right) \rightarrow 0$, as $k \rightarrow \infty$. This together with (41) gives $D_{f}\left(p, x_{m_{k}+1}\right) \rightarrow 0$, as $k \rightarrow \infty$. But $D_{f}\left(p, x_{k}\right) \leq D_{f}\left(p, x_{m_{k}+1}\right)$, for all $k \in N$; thus we obtain that $x_{k} \rightarrow p$. Therefore, from the above two cases, we can conclude that $\left\{x_{n}\right\}$ converges strongly to $p=P_{\mathscr{F}}^{f}(u)$ and the proof is complete.

If, in Theorem 14, we consider a single quasi-Bregman nonexpansive mapping, we get the following corollary.

Corollary 15. Let $f: E \rightarrow \mathbb{R}$ be a coercive Legendre function which is bounded, uniformly Fréchet differentiable, and totally convex on bounded subsets of $E$. Let $C$ be a nonempty, closed, and convex subset of int ( $\operatorname{dom} f$ ) and let $T: C \rightarrow C$ be a quasiBregman nonexpansive mapping such that $\widehat{F}(T)=F(T) \neq \emptyset$. Let $\left\{x_{n}\right\}$ be a sequence generated by

$$
\begin{gathered}
y_{n}=P_{C}^{f} \nabla f^{*}\left(\alpha_{n} \nabla f(u)+\left(1-\alpha_{n}\right) \nabla f\left(x_{n}\right)\right), \\
x_{n+1}=\nabla f^{*}\left(\beta \nabla f\left(y_{n}\right)+(1-\beta) \nabla f\left(T y_{n}\right)\right), \quad \forall n \geq 0,
\end{gathered}
$$

where $\left\{\alpha_{n}\right\} \subset(0,1)$ and $\beta \in(0,1)$ satisfying $\lim _{n \rightarrow \infty} \alpha_{n}=0$ and $\sum_{n=1}^{\infty}=\infty$. Then $\left\{x_{n}\right\}$ converges strongly to $p=P_{F(T)}^{f}(u)$.

If, in Theorem 14, we assume that each $T_{i}$, for $i \in$ $\{1,2, \ldots, N\}$, is Bregman relatively nonexpansive mapping, then we have that $\widehat{F}\left(T_{i}\right)=F\left(T_{i}\right)$ for each $i \in\{1,2, \ldots, N\}$. Thus, we get the following corollary.

Corollary 16. Let $f: E \rightarrow \mathbb{R}$ be a strongly coercive Legendre function which is bounded, uniformly Fréchet differentiable, and totally convex on bounded subsets of E. Let $C$ be a nonempty, closed, and convex subset of int(dom $f$ ) and let $T_{i}: C \rightarrow C$, for $i=1,2, \ldots, N$, be a finite family of Bregman relatively nonexpansive mappings. Assume that $\mathscr{F}:=$ $\bigcap_{i=1}^{N} F\left(T_{i}\right)$ is nonempty. For $u, x_{0} \in C$ let $\left\{x_{n}\right\}$ be a sequence generated by

$$
\begin{aligned}
y_{n} & =P_{C}^{f} \nabla f^{*}\left(\alpha_{n} \nabla f(u)+\left(1-\alpha_{n}\right) \nabla f\left(x_{n}\right)\right), \\
x_{n+1} & =\nabla f^{*}\left(\beta_{0} \nabla f\left(y_{n}\right)+\sum_{i=1}^{N} \beta_{i} \nabla f\left(T_{i} y_{n}\right)\right), \quad \forall n \geq 0,
\end{aligned}
$$


where $\left\{\alpha_{n}\right\} \subset(0,1)$ and $\left\{\beta_{i}\right\}_{i=0}^{N} \subset[c, d] \subset(0,1)$ satisfying $\lim _{n \rightarrow \infty} \alpha_{n}=0, \sum_{n=1}^{\infty} \alpha_{n}=\infty$, and $\sum_{i=0}^{N} \beta_{i}=1$. Then, $\left\{x_{n}\right\}$ converges strongly to $p=P_{\mathscr{F}}^{f}(u)$.

If, in Theorem 14, we assume that each $T_{i}(i=1,2, \ldots, N)$ is Bregman firmly nonexpansive, then we get the following corollary.

Corollary 17. Let $f: E \rightarrow \mathbb{R}$ be a strongly coercive Legendre function which is bounded, uniformly Fréchet differentiable, and totally convex on bounded subsets of $E$. Let $C$ be a nonempty, closed, and convex subset of $\operatorname{int}(\operatorname{dom} f)$ and let $T_{i}: C \rightarrow C$, for $i=1,2, \ldots, N$, be a finite family of Bregman firmly nonexpansive mappings with $\bigcap_{i=1}^{N} F\left(T_{i}\right) \neq \emptyset$. Let $\left\{x_{n}\right\}$ be a sequence generated by

$$
\begin{gathered}
y_{n}=P_{C}^{f} \nabla f^{*}\left(\alpha_{n} \nabla f(u)+\left(1-\alpha_{n}\right) \nabla f\left(x_{n}\right)\right), \\
x_{n+1}=\nabla f^{*}\left(\beta_{0} \nabla f\left(y_{n}\right)+\sum_{i=1}^{N} \beta_{i} \nabla f\left(T_{i} y_{n}\right)\right), \quad \forall n \geq 0,
\end{gathered}
$$

where $\left\{\alpha_{n}\right\} \subset(0,1)$ and $\left\{\beta_{i}\right\}_{i=0}^{N} \subset[c, d] \subset(0,1)$ satisfying $\lim _{n \rightarrow \infty} \alpha_{n}=0, \sum_{n=1}^{\infty} \alpha_{n}=\infty$, and $\sum_{i=0}^{N} \beta_{i}=1$. Then $\left\{x_{n}\right\}$ converges strongly to $p=P_{\mathscr{F}}^{f}(u)$.

\section{Applications}

4.1. Equilibrium Problems. Let $f: E \rightarrow(-\infty,+\infty]$ be a coercive Legendre function. Let $C$ be a nonempty, closed, and convex subset of $\operatorname{int}(\operatorname{dom} f)$. Let $H: C \times C \rightarrow \mathbb{R}$ be a bifunction with the following conditions (see example [38]).

(B1) $H(x, x)=0$, for all $x \in C$;

(B2) $H$ is monotone; that is, $H(x, y)+H(y, x) \leq 0$, for all $x, y \in C$

(B3) for all $x, y, z \in C, \lim \sup _{t \rightarrow 0^{+}} H(t z+(1-t) x, y) \leq$ $H(x, y)$;

(B4) for each $x \in C, H(x, \cdot)$ is convex and lower semicontinuous.

The equilibrium problem corresponding to $H$ is to find $x^{*} \in$ $C$ such that

$$
H\left(x^{*}, y\right) \geq 0, \quad \forall y \in C .
$$

The set of solutions of (47) is denoted by $\operatorname{EP}(H)$. Equilibrium problem is a unified model of several problems, namely, variational inequality problem, complementary problem, saddle point problem, optimization problem, fixed point problem, and so forth; see [20, 30, 38-43].

The resolvent of a bifunction $H: C \times C \rightarrow \mathbb{R}[39]$ is the operator $\operatorname{Res}_{H}^{f}: E \rightarrow 2^{C}$, defined by

$$
\begin{aligned}
\operatorname{Res}_{H}^{f}(x)=\{z \in C & : H(z, y) \\
& +\langle\nabla f(z)-\nabla f(x), y-z\rangle \geq 0, \forall y \in C\} .
\end{aligned}
$$

We know the following lemma in [23].
Lemma 18. Let $f: E \rightarrow(-\infty,+\infty]$ be a coercive Legendre function. Let $C$ be a nonempty, closed, and convex subset of $\operatorname{int}(\operatorname{dom} f)$. If the bifunction $H: C \times C \rightarrow \mathbb{R}$ satisfies conditions (B1)-(B4), then

(1) $\operatorname{Res}_{H}^{f}$ is single-valued and $\left.\operatorname{dom}\left(\operatorname{Res}_{g}^{f}\right)\right)=E$;

(2) $\operatorname{Res}_{H}^{f}$ is a Bregman firmly nonexpansive mapping;

(3) $E P(H)$ is a closed and convex subset of $C$ and $E P(H)=$ $F\left(\operatorname{Res}_{H}^{f}\right)$;

(4) For all $x \in E$ and for all $u \in F\left(\operatorname{Res}_{H}^{f}\right)$, we have

$$
D_{f}\left(u, \operatorname{Res}_{H}^{f}(x)\right)+D_{f}\left(\operatorname{Res}_{H}^{f}(x), x\right) \leq D_{f}(u, x) .
$$

In addition, if $f$ is uniformly Fréchet differentiable and bounded on bounded subsets of $E$, then by Reich and Sabach [5] we have that $F\left(\operatorname{Res}_{H}^{f}\right)=\widehat{F}\left(\operatorname{Res}_{H}^{f}\right)$. Thus, considering $T_{i}=$ $\operatorname{Res}_{H_{i}}^{f}$, for $i=1,2, \ldots, N$, in Corollary 17, we get the following result.

Theorem 19. Let $f: E \rightarrow \mathbb{R}$ be a strongly coercive Legendre function which is bounded, uniformly Fréchet differentiable, and totally convex on bounded subsets of $E$. Let $C$ be a nonempty, closed, and convex subset of $\operatorname{int}(\operatorname{dom} f)$ and let $H_{i}: C \rightarrow C$, for $i=1,2, \ldots, N$, be bifunctions which satisfy the conditions (B1)-(B4) and $\mathscr{F}:=\bigcap_{i=1}^{N} E P\left(H_{i}\right)$ is nonempty. For $x_{0} \in C$ let $\left\{x_{n}\right\}$ be a sequence generated by

$$
\begin{gathered}
y_{n}=\nabla f^{*}\left(\alpha_{n} \nabla f(u)+\left(1-\alpha_{n}\right) \nabla f\left(x_{n}\right)\right), \\
x_{n+1}=\nabla f^{*}\left(\beta_{0} \nabla f\left(y_{n}\right)+\sum_{i=1}^{N} \beta_{i} \nabla f\left(T_{i} y_{n}\right)\right), \quad \forall n \geq 0,
\end{gathered}
$$

where $T_{i}=\operatorname{Res}_{H_{i}}^{f},\left\{\alpha_{n}\right\} \subset(0,1)$, and $\left\{\beta_{i}\right\}_{i=0}^{N} \subset[c, d] \subset(0,1)$ satisfy $\lim _{n \rightarrow \infty} \alpha_{n}=0, \sum_{n=1}^{\infty} \alpha_{n}=\infty$, and $\sum_{i=0}^{N} \beta_{i}=1$. Then, $\left\{x_{n}\right\}$ converges strongly to $p=P_{\mathscr{F}}^{f}(u)$.

4.2. Zeroes of Maximal Monotone Operators. In this section we present an algorithm for finding a common zero of a finite family of maximal monotone mappings.

Let $A: E \rightarrow 2^{E^{*}}$ be a mapping with range $R(A)=\left\{x^{*} \in\right.$ $\left.E^{*}: x^{*} \in A x\right\}$ and domain $D(A)=\{x \in E: A x \neq \emptyset\}$. Then, $A$ is said to be monotone if, for any $x, y \in \operatorname{dom}(A)$, we have

$$
x^{*} \in A x, y^{*} \in A y \Longrightarrow\left\langle x-y, x^{*}-y^{*}\right\rangle \geq 0 .
$$

It is said to be maximal monotone if $A$ is monotone and the graph of $A$ is not a proper subset of the graph of any other monotone mappings, where graph of $A$ is given by $G(A):=$ $\left\{\left(x, x^{*}\right) \in E \times E^{*}: x^{*} \in A x\right\}$. It is known that if $A$ is maximal monotone, then the set $A^{-1}(0)=\{z \in E: 0 \in A z\}$ is closed and convex.

Let $A: C \subseteq E \rightarrow 2^{E^{*}}$ be maximal monotone mapping and $f$ is Legendre function which is bounded, uniformly Fréchet differentiable on bounded subsets of $E$. The resolvent 
of $A$ with respect to $f$ is the mapping $\operatorname{Res}_{A}^{f}: E \rightarrow 2^{E}$ defined by

$$
\operatorname{Res}_{A}^{f}=(\nabla f+A)^{-1} \circ \nabla f \text {. }
$$

It is known that $\operatorname{Res}_{A}^{f}$ is single-valued, Bregman firmly nonexpansive and $F\left(\operatorname{Res}_{A}^{f}\right)=A^{-1}(0)$ (see [17]). Furthermore, the result by Reich and Sabach [5] implies that $F\left(\operatorname{Res}_{A}^{f}\right)=$ $\widehat{F}\left(\operatorname{Res}_{A}^{f}\right)$. If, in Theorem 14, we assume that $T_{i}=\operatorname{Res}_{A_{i}}^{f}$, then we obtain an algorithm for finding a common zero of a finite family of maximal monotone mappings.

Theorem 20. Let $f: E \rightarrow \mathbb{R}$ be a Legendre function which is bounded, uniformly Fréchet differentiable, and totally convex on bounded subsets of E. Let $C$ be a nonempty, closed, and convex subset of $\operatorname{int}(\operatorname{dom} f)$ and let $A_{i}: C \rightarrow 2^{E^{*}}, i=$ $1,2, \ldots, N$, be $N$ maximal monotone mappings with $\mathscr{F}:=$ $\bigcap_{i=1}^{N} A_{i}^{-1}(0) \neq \emptyset$. Then, for each $x_{1}, u \in E$, the sequence $\left\{x_{n}\right\}$ is defined by

$$
\begin{gathered}
y_{n}=\nabla f^{*}\left(\alpha_{n} \nabla f(u)+\left(1-\alpha_{n}\right) \nabla f\left(x_{n}\right)\right), \\
x_{n+1}=\nabla f^{*}\left(\beta_{0} \nabla f\left(y_{n}\right)+\sum_{i=1}^{N} \beta_{i} \nabla f\left(T_{i} y_{n}\right)\right), \quad \forall n \geq 0,
\end{gathered}
$$

where $T_{i}=\operatorname{Res}_{H_{i}}^{f},\left\{\alpha_{n}\right\} \subset(0,1)$, and $\left\{\beta_{i}\right\}_{i=0}^{N} \subset[c, d] \subset(0,1)$ satisfy $\lim _{n \rightarrow \infty} \alpha_{n}=0, \sum_{n=1}^{\infty} \alpha_{n}=\infty$, and $\sum_{i=0}^{N} \beta_{i}=1$. Then, $\left\{x_{n}\right\}$ converges strongly to $p=P_{\mathscr{F}}^{f}(u)$.

For a common point of a solution of equilibrium problem and a zero of maximal monotone mapping we have the following corollary.

Corollary 21. Let $f: E \rightarrow \mathbb{R}$ be a strongly coercive Legendre function which is bounded, uniformly Fréchet differentiable, and totally convex on bounded subsets of $E$. Let $C$ be a nonempty, closed, and convex subset of $\operatorname{int}(\operatorname{dom} f)$ and let $H: C \rightarrow C$ be bifunction which satisfy the conditions (B1)(B4) and let $A: C \rightarrow 2^{E^{*}}$ be a maximal monotone mapping. Assume that $\mathscr{F}:=E P\left(H_{i}\right) \cap A^{-1}(0)$ is nonempty. For $x_{0} \in C$ let $\left\{x_{n}\right\}$ be a sequence generated by

$$
\begin{array}{r}
y_{n}=\nabla f^{*}\left(\alpha_{n} \nabla f(u)+\left(1-\alpha_{n}\right) \nabla f\left(x_{n}\right)\right), \\
x_{n+1}=\nabla f^{*}\left(\beta_{0} \nabla f\left(y_{n}\right)+\beta_{1} \nabla f\left(\operatorname{Res}_{H}^{f} y_{n}\right)\right. \\
\left.+\beta_{2} \nabla f\left(\operatorname{Res}_{A}^{f} y_{n}\right)\right), \quad \forall n \geq 0,
\end{array}
$$

where $\left\{\alpha_{n}\right\} \subset(0,1)$ and $\left\{\beta_{i}\right\}_{i=1}^{2} \subset[c, d] \subset(0,1)$ satisfying $\lim _{n \rightarrow \infty} \alpha_{n}=0, \sum_{n=1}^{\infty} \alpha_{n}=\infty$, and $\sum_{i=0}^{2} \beta_{i}=1$. Then, $\left\{x_{n}\right\}$ converges strongly to $p=P_{\mathscr{F}}^{f}(u)$.

Remark 22. Corollary 17 and Corollary 4.3 improve Theorem 1 of Reich and Sabach [23] and Theorem 4.2 of Reich and Sabach [4], respectively, in the sense that at each stage the computation of $C_{n}$ or $Q_{n}$ is not required.

\section{Conflict of Interests}

The authors declare that there is no conflict of interests regarding the publication of this paper.

\section{Acknowledgments}

This project was funded by the Deanship of Scientific Research (DSR), King Abdulaziz University, Jeddah, under grant no. 170/130/1434. The authors, therefore, acknowledge with thanks DSR technical and financial support. Also, they would like to thank the anonymous reviewers for their valuable comments and suggestions.

\section{References}

[1] L. M. Brègman, "A relaxation method of finding a common point of convex sets and its application to the solution of problems in convex programming," USSR Computational Mathematics and Mathematical Physics, vol. 7, pp. 620-631, 1967.

[2] Y. I. Alber, "Metric and generalized projection operators in Banach spaces: properties and applications," in Theory and Applications of Nonlinear Operators of Accretive and Monotone Type, Lecture Notes in Pure and Applied Mathematics, pp. 1550, 1996

[3] S. Reich, "A weak convergence theorem for the alternating method with Bregman distances," in Theory and Applications of Nonlinear Operators of Accretive and Monotone Type, pp. 313318, Marcel Dekker, New York, NY, USA, 1996.

[4] S. Reich and S. Sabach, "Two strong convergence theorems for a proximal method in reflexive Banach spaces," Numerical Functional Analysis and Optimization, vol. 31, no. 1-3, pp. 2244, 2010.

[5] S. Reich and S. Sabach, "Existence and approximation of fixed points of Bregman firmly nonexpansive mappings in reflexive Banach spaces," in Fixed-Point Algorithms for Inverse Problems in Science and Engineering, Springer Optimization and Its Applications, pp. 301-316, Springer, New York, NY, USA, 2011.

[6] F. E. Browder, "Convergence of approximants to fixed points of nonexpansive non-linear mappings in Banach spaces," Archive for Rational Mechanics and Analysis, vol. 24, pp. 82-90, 1967.

[7] B. Halpern, "Fixed points of nonexpanding maps," Bulletin of the American Mathematical Society, vol. 73, pp. 957-961, 1967.

[8] S. Reich, "Strong convergence theorems for resolvents of accretive operators in Banach spaces," Journal of Mathematical Analysis and Applications, vol. 75, no. 1, pp. 287-292, 1980.

[9] H. Zegeye and N. Shahzad, "Strong convergence theorems for a finite family of nonexpansive mappings and semigroups via the hybrid method," Nonlinear Analysis. Theory, Methods Applications, vol. 72, no. 1, pp. 325-329, 2010.

[10] H. Zegeye, N. Shahzad, and M. A. Alghamdi, "Convergence of Ishikawa's iteration method for pseudocontractive mappings," Nonlinear Analysis: Theory, Methods \& Applications, vol. 74, no. 18, pp. 7304-7311, 2011.

[11] H. Zegeye, N. Shahzad, and M. A. Alghamdi, "Minimumnorm fixed point of pseudocontractive mappings," Abstract and Applied Analysis, vol. 2012, Article ID 926017, 15 pages, 2012.

[12] H. Zegeye and N. Shahzad, "Strong convergence theorems for monotone mappings and relatively weak nonexpansive mappings," Nonlinear Analysis: Theory, Methods \& Applications, vol. 70, no. 7, pp. 2707-2716, 2009. 
[13] H. Zegeye and N. Shahzad, "A hybrid scheme for finite families of equilibrium, variational inequality and fixed point problems," Nonlinear Analysis: Theory, Methods and Applications, vol. 74, no. 1, pp. 263-272, 2011.

[14] D. R. Sahu, V. Colao, and G. Marino, "Strong convergence theorems for approximating common fixed points of families of nonexpansive mappings and applications," Journal of Global Optimization, vol. 56, no. 4, pp. 1631-1651, 2013.

[15] F. Cianciaruso, G. Marino, and L. Muglia, "Iterative methods for equilibrium and fixed point problems for nonexpansive semigroups in Hilbert spaces," Journal of Optimization Theory and Applications, vol. 146, no. 2, pp. 491-509, 2010.

[16] F. Cianciaruso, G. Marino, and L. Muglia, "Ishikawa iterations for equilibrium and fixed point problems for nonexpansive mappings in Hilbert spaces," Fixed Point Theory, vol. 9, no. 2, pp. 449-464, 2008.

[17] H. H. Bauschke, J. M. Borwein, and P. L. Combettes, "Bregman monotone optimization algorithms," SIAM Journal on Control and Optimization, vol. 42, no. 2, pp. 596-636, 2003.

[18] D. Butnariu and E. Resmerita, "Bregman distances, totally convex functions, and a method for solving operator equations in Banach spaces," Abstract and Applied Analysis, vol. 2006, Article ID 84919, 39 pages, 2006.

[19] N. Shahzad, H. Zegeye, and A. Alotaibi, "Convergence results for a common solution of a finite family of variational inequality problems for monotone mappings with Bregman distance function," Fixed Point Theory and Applications, vol. 2013, article 343, 2013.

[20] H. Zegeye and N. Shahzad, "A hybrid approximation method for equilibrium, variational inequality and fixed point problems," Nonlinear Analysis. Hybrid Systems, vol. 4, no. 4, pp. 619-630, 2010.

[21] H. Zegeye and N. Shahzad, "Approximating common solution of variational inequality problems for two monotone mappings in Banach spaces," Optimization Letters, vol. 5, no. 4, pp. 691704, 2011.

[22] S. Reich and S. Sabach, "A projection method for solving nonlinear problems in reflexive Banach spaces," Journal of Fixed Point Theory and Applications, vol. 9, no. 1, pp. 101-116, 2011.

[23] S. Reich and S. Sabach, "Two strong convergence theorems for Bregman strongly nonexpansive operators in reflexive Banach spaces," Nonlinear Analysis: Theory, Methods \& Applications, vol. 73, no. 1, pp. 122-135, 2010.

[24] R. P. Phelps, Convex Functions, Monotone Operators and Differentiability, vol. 1364 of Lecture Notes in Mathematics, Springer, Berlin, Germnay, 2nd edition, 1993.

[25] H. H. Bauschke, J. M. Borwein, and P. L. Combettes, "Essential smoothness, essential strict convexity, and Legendre functions in Banach spaces," Communications in Contemporary Mathematics, vol. 3, no. 4, pp. 615-647, 2001.

[26] J. F. Bonnans and A. Shapiro, Perturbation Analysis of Optimization Problems, Springer, New York, NY, USA, 2000.

[27] C. Zalinescu, Convex Analysis in General Vector Spaces, World Scientific, River Edge, NJ, USA, 2002.

[28] E. Naraghirad and J. Yao, "Bregman weak relatively nonexpansive mappings in Banach spaces," Fixed Point Theory and Applications, vol. 2013, article 141, 2013.

[29] V. Martín-Márquez, S. Reich, and S. Sabach, "Bregman strongly nonexpansive operators in reflexive Banach spaces," Journal of Mathematical Analysis and Applications, vol. 400, no. 2, pp. 597614, 2013.
[30] J.-B. Hiriart-Urruty and C. Lemarchal, Convex Analysis and Minimization Algorithms II, vol. 306 of Grundlehren der mathematischen Wissenschaften, Springer, 1993.

[31] D. Butnariu and A. N. Iusem, Totally Convex Functions for Fixed Points Computation and Infinite Dimensional Optimization, Kluwer Academic Publishers, Dordrecht, The Netherlands, 2000.

[32] H. H. Bauschke, "The approximation of fixed points of compositions of nonexpansive mappings in Hilbert space," Journal of Mathematical Analysis and Applications, vol. 202, no. 1, pp. 150159, 1996.

[33] S. Reich and S. Sabach, "A strong convergence theorem for a proximal-type algorithm in reflexive Banach spaces," Journal of Nonlinear and Convex Analysis., vol. 10, no. 3, pp. 471-485, 2009.

[34] Y. Censor and A. Lent, "An iterative row-action method for interval convex programming," Journal of Optimization Theory and Applications, vol. 34, no. 3, pp. 321-353, 1981.

[35] F. Kohsaka and W. Takahashi, "Proximal point algorithms with Bregman functions in Banach spaces," Journal of Nonlinear and Convex Analysis, vol. 6, no. 3, pp. 505-523, 2005.

[36] $\mathrm{H}$. Xu, "Another control condition in an iterative method for nonexpansive mappings," Bulletin of the Australian Mathematical Society, vol. 65, no. 1, pp. 109-113, 2002.

[37] P. Maingé, "Strong convergence of projected subgradient methods for nonsmooth and nonstrictly convex minimization," SetValued Analysis, vol. 16, no. 7-8, pp. 899-912, 2008.

[38] E. Blum and W. Oettli, "From optimization and variational inequalities to equilibrium problems," The Mathematics Student, vol. 63, no. 1-4, pp. 123-145, 1994.

[39] P. L. Combettes and S. A. Hirstoaga, "Equilibrium programming in Hilbert spaces," Journal of Nonlinear and Convex Analysis, vol. 6, no. 1, pp. 117-136, 2005.

[40] H. Zegeye and N. Shahzad, "Convergence theorems for a common point of solutions of equilibrium and fixed point of relatively nonexpansive multivalued mapping problems," Abstract and Applied Analysis, vol. 2012, Article ID 859598, 16 pages, 2012.

[41] H. Zegeye, N. Shahzad, and M. A. Alghamdi, "Strong convergence theorems for a common point of solution of variational inequality, solutions of equilibrium and fixed point problems," Fixed Point Theory and Applications, vol. 2012, article 119, 17 pages, 2012.

[42] H. Zegeye and N. Shahzad, "Strong convergence theorems for a solution of a finite family of Bregman weak relatively nonexpansive mappings in reflexive Banach spaces," The Scientific World Journal, vol. 2014, Article ID 493450, 8 pages, 2014.

[43] H. Zegeye and N. Shahzad, "Strong convergence theorems for a solution of finite families of equilibrium and variational inequality problems," Optimization, vol. 63, no. 2, pp. 207-223, 2014. 


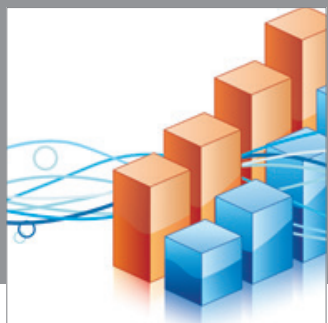

Advances in

Operations Research

mansans

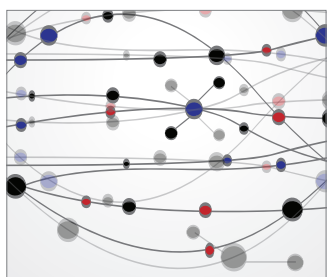

The Scientific World Journal
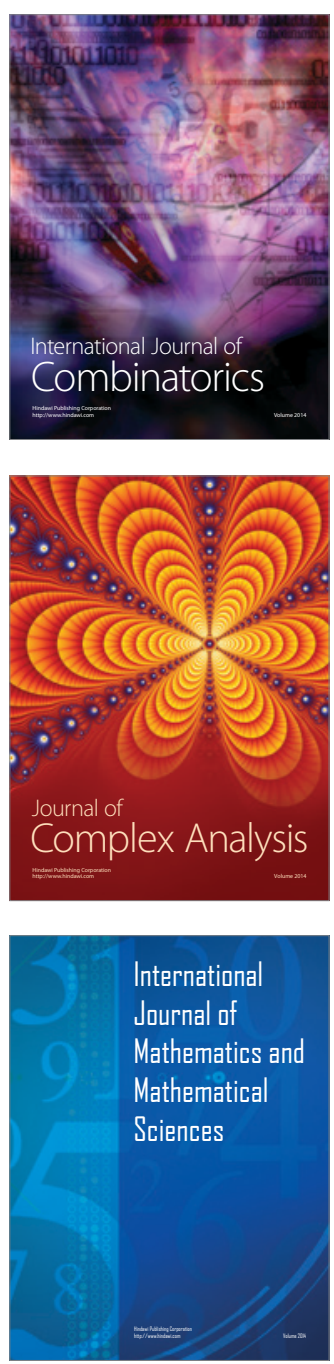
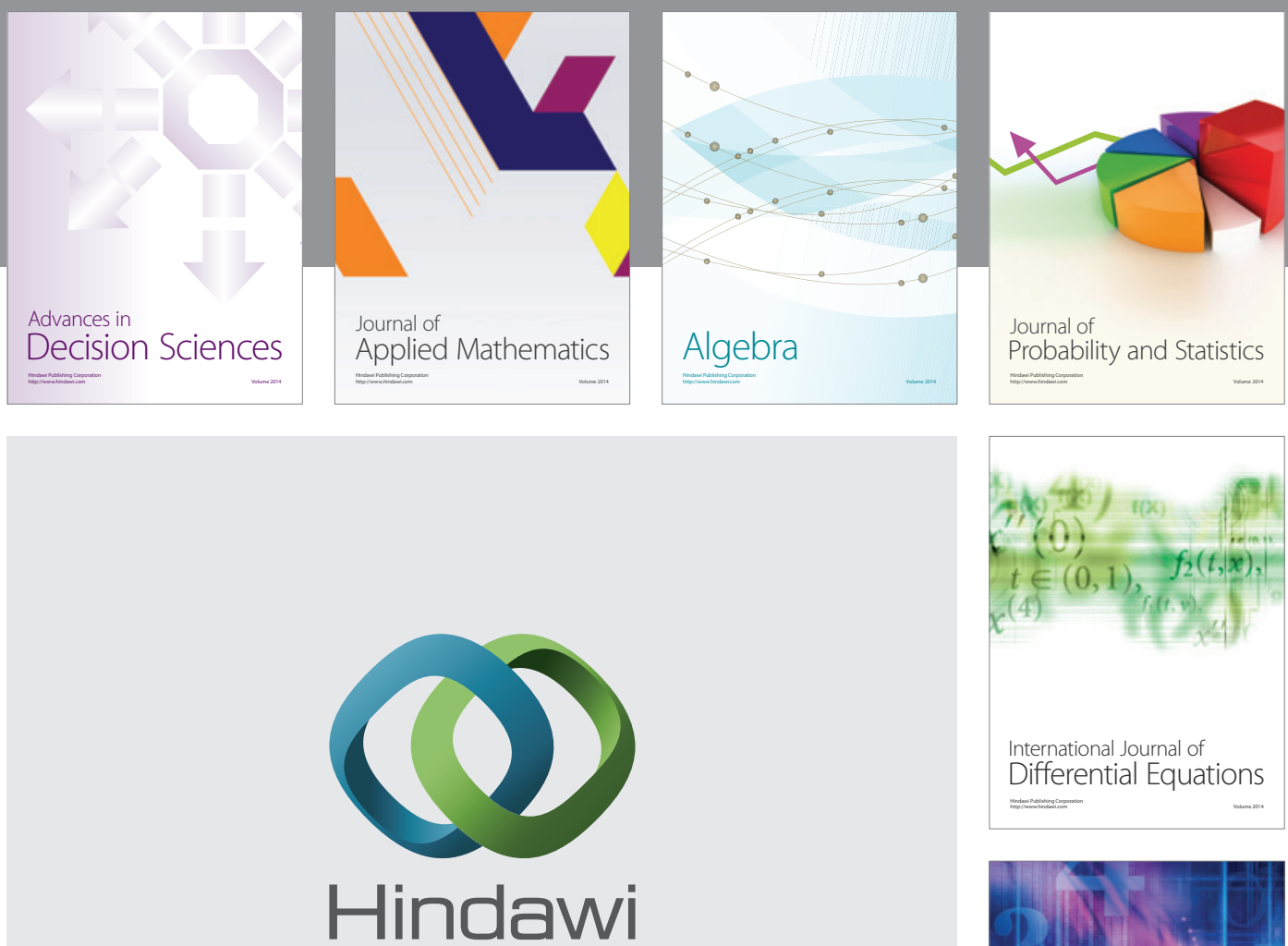

Submit your manuscripts at http://www.hindawi.com
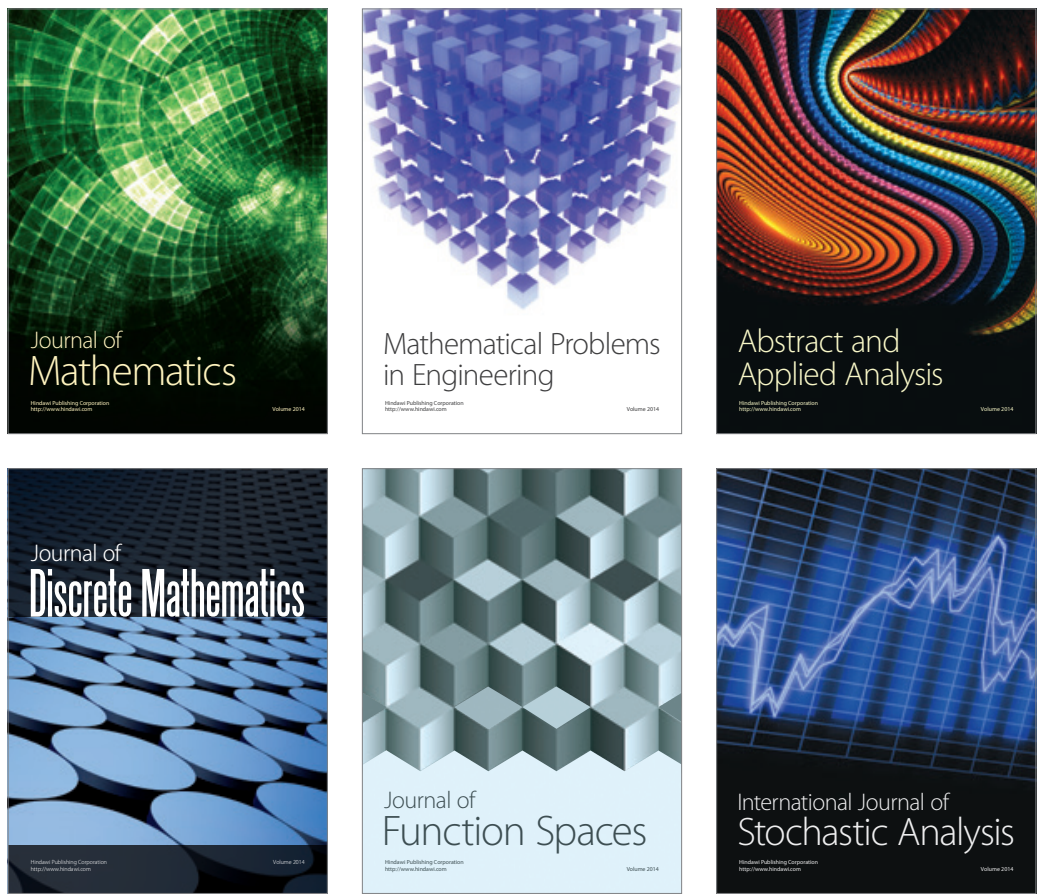

Journal of

Function Spaces

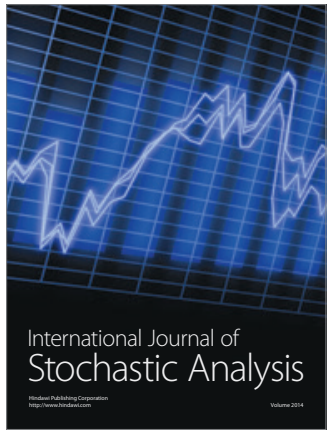

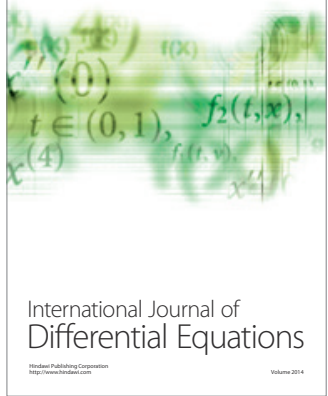
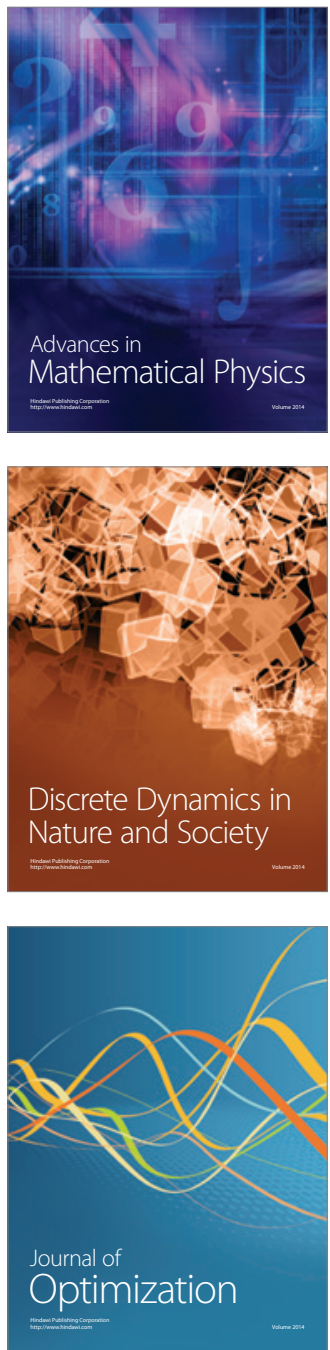